\title{
Psychological morbidity and impaired quality of life in patients with stable treatment for primary adrenal insufficiency: cross-sectional study and review of the literature
}

\author{
Jitske Tiemensma ${ }^{1,2, *}$, Cornelie D Andela ${ }^{1, *}$, Ad A Kaptein ${ }^{3}$, Johannes A Romijn ${ }^{4}$, \\ Roos C van der Mast ${ }^{5}$, Nienke R Biermasz ${ }^{1}$ and Alberto M Pereira ${ }^{1}$ \\ ${ }^{1}$ Department of Endocrinology and Metabolism, C7-Q, Center for Endocrine Tumors Leiden (CETL), Leiden \\ University Medical Center, PO Box 9600, 2300 RC Leiden, The Netherlands, ${ }^{2}$ Psychological Science, University of \\ California Merced, Merced, California, USA, ${ }^{3}$ Department of Medical Psychology, Leiden University Medical Center, \\ PO Box 9600, 2300 RC Leiden, The Netherlands, ${ }^{4}$ Department of Medicine, Academic Medical Center, Amsterdam, \\ The Netherlands and ${ }^{5}$ Department of Psychiatry, Leiden University Medical Center, PO Box 9600, 2300 RC Leiden, \\ The Netherlands \\ *(J Tiemensma and C D Andela contributed equally to this work)
}

\author{
Correspondence \\ should be addressed \\ to C D Andela \\ Email \\ c.d.andela@lumc.nl
}

\begin{abstract}
Context: A high prevalence of psychological morbidity and maladaptive personality as well as impaired quality of life (QoL) is observed in patients with and without hydrocortisone dependency following (cured) Cushing's syndrome. However, it is currently unclear whether a similar pattern is present in patients with chronic glucocorticoid replacement for primary adrenal insufficiency (PAI).

Objective: To evaluate psychological functioning, personality traits, and QoL in patients with PAI.

Design and subjects: A cross-sectional study including 54 patients with stable treatment for PAI and 54 healthy matched controls. Both patients and controls completed questionnaires on psychological functioning (Apathy Scale, Irritability Scale, Mood and Anxiety Symptoms Questionnaire short form, and Hospital Anxiety and Depression Scale), personality traits (Dimensional Assessment of Personality Pathology short form), and QoL (Multidimensional Fatigue Inventory, Short Form 36, EuroQoL-5D, Nottingham Health Profile, and Physical Symptom Checklist).

Results: Patients with PAI suffered from more psychological morbidity (i.e. irritability and somatic arousal) and QoL impairments compared with controls (all $P<0.01$ ). There were no differences regarding maladaptive personality traits between patients and controls. However, there was a strong and consistent positive association between the daily hydrocortisone dose and prevalence of maladaptive personality traits (i.e. identity problems, cognitive distortion, compulsivity, restricted expression, callousness, oppositionality, rejection, conduct problems, social avoidance, narcissism, and insecure attachment, all $P<0.05)$. There was also a strong relation between the mean daily hydrocortisone dose and both psychological morbidity (i.e. depression, $P<0.05$ ) and QoL impairments (i.e. general health perception, several measures of physical functioning, and vitality, all $P<0.05$ ).

Conclusion: Patients on stable glucocorticoid replacement therapy for PAl report psychological morbidity and impaired QoL. Psychological morbidity, impaired QoL, and maladaptive personality traits were all associated with higher dosages of hydrocortisone.
\end{abstract}




\section{Introduction}

Primary adrenal insufficiency (PAI) is characterized by insufficient secretion of glucocorticoids and mineralocorticoids, most frequently caused by autoimmunity or following bilateral adrenalectomy. Replacement therapy consists of hydrocortisone, fludrocortisone, and sometimes, additional DHEA replacement.

Cortisol has a crucial function in the CNS via stimulation of both the mineralocorticoid receptor (MR) and glucocorticoid receptor (GR). An appropriate balance between the activation of these two receptors is necessary for adequate stress responses, including behavioral adaptations. Imbalance between MR and GR activations might enhance vulnerability to disease in predisposed individuals. The current notion is that the effects of glucocorticoids binding to MR and GR include an inverted u-shape dose-response curve, indicating that both pathologically low and high cortisol levels negatively affect the mediating functions of these receptors as is the absence of physiological circadian pulsatile secretion (1). The negative influence of glucocorticoid excess on psychological functioning in humans is clearly evident during active Cushing's disease because serious co-morbid psychopathology, such as major depression and anxiety, is prevalent (2). Although these symptoms improve substantially after correction of cortisol excess, consistent residual impairments persist even after prolonged cure of cortisol excess. This is reflected by an increased prevalence of psychopathology and maladaptive personality traits, as well as impairments in quality of life (QoL) $(3,4,5,6,7)$ in many patients, either hydrocortisone dependent or independent.

Conversely, it is possible that previous exposure to insufficient glucocorticoid levels and recent imperfections in replacement therapy in mimicking the pulsatile secretion of cortisol, such as in PAI, may also be associated with persistent psychosocial effects, considering the inverted u-shape of optimal corticosteroid receptor function. However, in contrast to the large number of reports on patients with Cushing's syndrome, less is known about the effects of previous insufficient cortisol exposure on psychological functioning and QoL in PAI (see Table 1 for an overview). Heijmans \& de Ridder (1998) (8) reported a significant relation between personality-related variables (i.e. optimism/pessimism, locus of control) and illness perceptions. However, there are no studies on personality traits in patients with PAI. To date, studies in patients with PAI have demonstrated impaired QoL $(9,10,11,12,13,14$, $15)$, and a higher risk for the development of affective disorders such as depression or bipolar disorder (16). The
QoL impairments in patients with PAI have been attributed, at least in part, to intrinsic imperfections of hormone replacement therapy (12). In accordance, some studies demonstrated a positive effect of DHEA replacement on QoL $(13,17,18,19)$. On the other hand, strategies aiming at adjusting cortisol replacement therapy mimicking a more diurnal profile by adjusting the time and frequency of hydrocortisone intake did not positively affect QoL $(9,11,20)$. Furthermore, dosages above $30 \mathrm{mg}$ hydrocortisone/day were associated with worse subjective health status (11).

Considering the limited amount of studies on psychological functioning in patients with PAI and the fact that studies on personality traits are lacking, the aim of the present study was to evaluate psychological functioning and personality traits, as well as QoL in patients with stable treatment for PAI. In accordance to previous studies, we hypothesized that patients with PAI not only would report impaired QoL, but also psychological morbidity, despite long-term stable replacement with hydrocortisone. Furthermore, we hypothesized that patients with PAI demonstrate maladaptive personality traits. The second aim was to explore a potential association between hydrocortisone intake and psychological functioning, personality traits, and QoL in patients with PAI.

\section{Patients and methods}

\section{Participants}

Patients with PAI were recruited via the Outpatient Clinic of the Department Endocrinology of the Leiden University Medical Center (LUMC) and by advertisement via the Dutch Adrenal Patient Society for Addison and Cushing Patients (NVACP; www.nvacp.nl). Thirty-nine patients were recruited from the patient network and 15 patients were recruited from the LUMC outpatient clinic. There were no differences regarding gender and age between patients derived from the patient network and patients derived from the outpatient clinic.

Patients with current or previous drug or alcohol abuse or with neurological problems were excluded. A total of 54 participants were included in this study ( 21 men and 33 women). The mean age of the patients was $50 \pm 12$ years. Each patient was asked to provide a control person of comparable gender, age ( \pm 10 years), and educational level in order to create a control group. The self-selection of controls enabled a perfect match for 
an additional parameter, i.e. social-economic status. Exclusion criteria for controls were present or previous drugs/alcohol abuse or neurological problems.

PAI had been diagnosed based on the classical clinical symptoms and biochemical confirmation of $\mathrm{AI}$ in the presence of increased adrenocorticotropic hormone (ACTH) concentrations. AI was diagnosed when basal cortisol concentrations were below the reference range of normal $(<0.12 \mu \mathrm{mol} / \mathrm{l})$ or below $500 \mathrm{nmol} / \mathrm{l}$ after stimulation with ACTH. Forty-four patients (82\%) had been diagnosed with PAI due to autoimmune disease with positive autoantibodies against adrenal cortex, five patients (9\%) had been diagnosed with PAI due to nonautoimmune causes (e.g. congenital adrenal aplasia and adrenal calcification), and two patients (4\%) were treated with bilateral adrenalectomy for pheochromocytomas. The origin of PAI was unknown for three patients (5\%).

All patients were on stable hydrocortisone and fludrocortisone replacement therapy for a mean duration of $10.1 \pm 8.5$ years (range, $2-38$ years), as prescribed by their individual physicians. Eighty-three percent of the patients also used fludrocortisone in addition to hydrocortisone. Additional medical therapy included DHEA (26\% of patients), levothyroxine for Hashimoto's thyroiditis (46\%), anti-hypertensive drugs (13\%), and oral contraceptives (9\%). Sixty-five percent of female patients were postmenopausal.

The Medical Ethics Committee of the LUMC approved the protocol and written informed consent was obtained from all subjects.

\section{Questionnaires}

Both patients and controls were asked to complete the following questionnaires on psychological functioning, personality traits, and QoL at home and to return the questionnaires in a prepaid envelope.

The Apathy Scale consists of 14 questions on a four point scale measuring different features of apathy in the previous 2 weeks. The score for each item ranges from 0 (no apathy) to 3 (maximum intensity of apathy). The total score ranges from 0 to 42 points, with higher scores indicating greater apathy. A total score $\geq 14$ points is being used to characterize subjects as apathetic $(21,22)$.

The Irritability Scale consists of 14 items measuring different features of irritability in the previous 2 weeks. The total score ranges from 0 to 42 points, with higher scores indicating greater irritability. A total score $\geq 14$ points is being used to characterize subjects as irritable (22).
The Mood and Anxiety Symptoms Questionnaire short form (MASQ-30) assesses symptoms that occur in mood and anxiety disorders subdivided into the three subscales: negative affect, lack of positive affect, and somatic arousal. The scores for each subscale range from 10 to 50, with higher scores indicating more severe negative affect, more positive affect, or more somatic arousal. There are no formal cutoff scores (23).

The Hospital Anxiety and Depression Scale (HADS) consists of 14 items, and both the anxiety and the depression subscale scores range from 0 to 21 points. Higher scores indicate more severe anxiety and/or depression. A score $>8$ points on one of the subscales is being used to characterize subjects as being anxious or depressed respectively $(24,25)$.

The Multidimensional Fatigue Inventory (MFI-20) assesses fatigue. Five different dimensions of fatigue are calculated: i) general fatigue, ii) physical fatigue, iii) reduced activity, iv) reduced motivation, and v) mental fatigue. Scores vary from 0 to 20 , with higher scores indicating greater fatigue (26).

The Short Form 36 (SF-36) assesses functional status and general well-being during the previous month $(23,24)$. The items cover nine health concepts: i) physical functioning, ii) social functioning, iii) role limitation (physical), iv) role limitation (emotional), v) mental health, vi) vitality, vii) pain, viii) general health perception, and ix) general perception of change in health. Scores are expressed on a $0-100$ scale and higher scores indicate a better QoL $(27,28)$.

The EuroQoL-5D (EQ-5D) assesses current health status reflected in five dimensions: mobility, self-care, usual activities, pain/discomfort, and anxiety/depression. Scores are expressed on a 1-3 scale per dimension, with higher scores indicating worse QoL. The questionnaire also includes a visual analog scale (VAS) which comprises a standard vertical $20 \mathrm{~cm}$ scale (similar to a thermometer) for recording an individual's rating for their current healthrelated well-being (29). The VAS score ranges from 0 to 100, with higher scores indicating a better health status.

The Nottingham Health Profile (NHP) assesses general well-being and consists of 38 yes/no questions, which are subdivided into six scales assessing impairments, i.e. pain (eight items), energy level (three items), sleep (five items), emotional reactions (nine items), social isolation (five items), and disability/functioning (eight items). Subscale scores are calculated as a weighted mean of the associated items and are expressed as a value between 0 and $1(30,31)$.

The Physical Symptom Checklist (PSC) assesess 55 physical symptoms that are mentioned in the DSM-III 


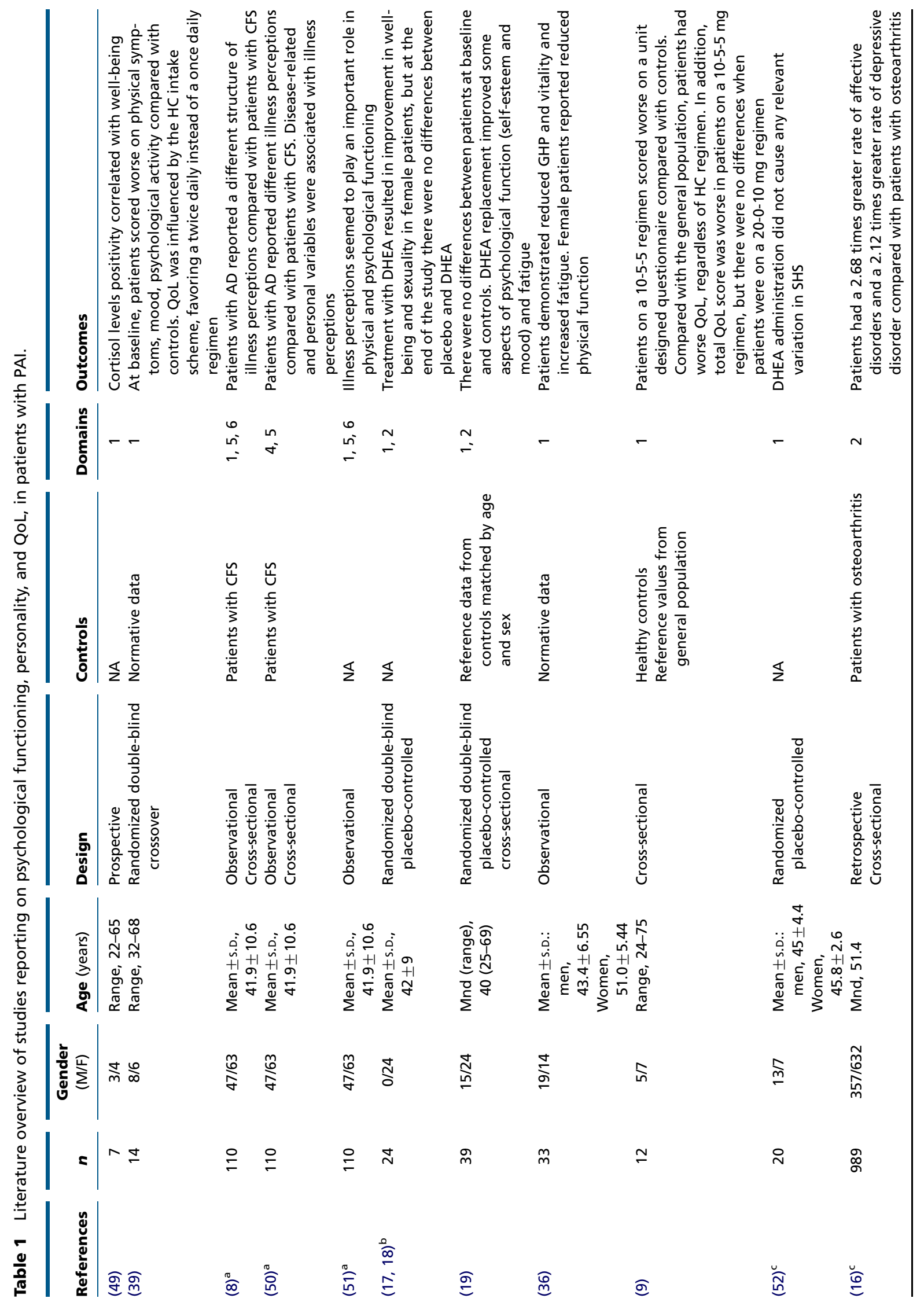



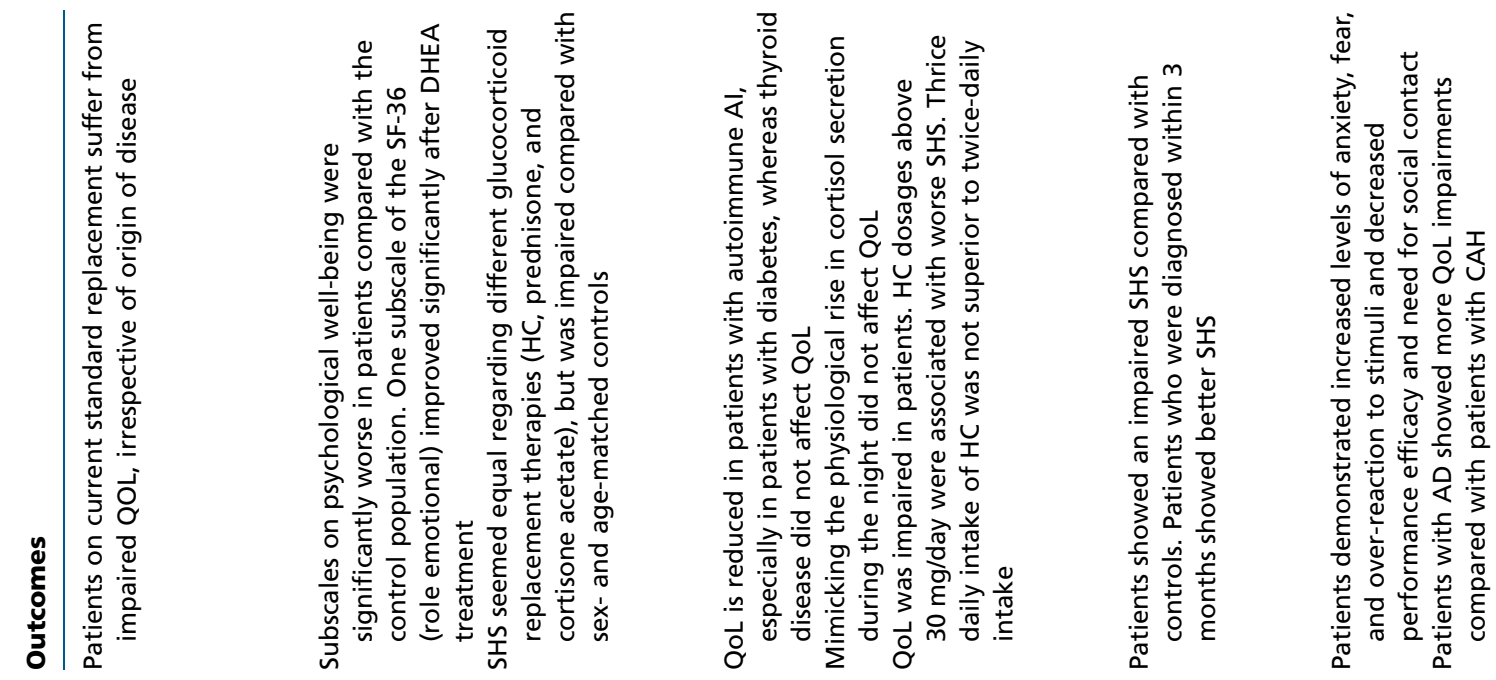

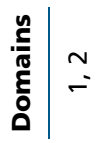
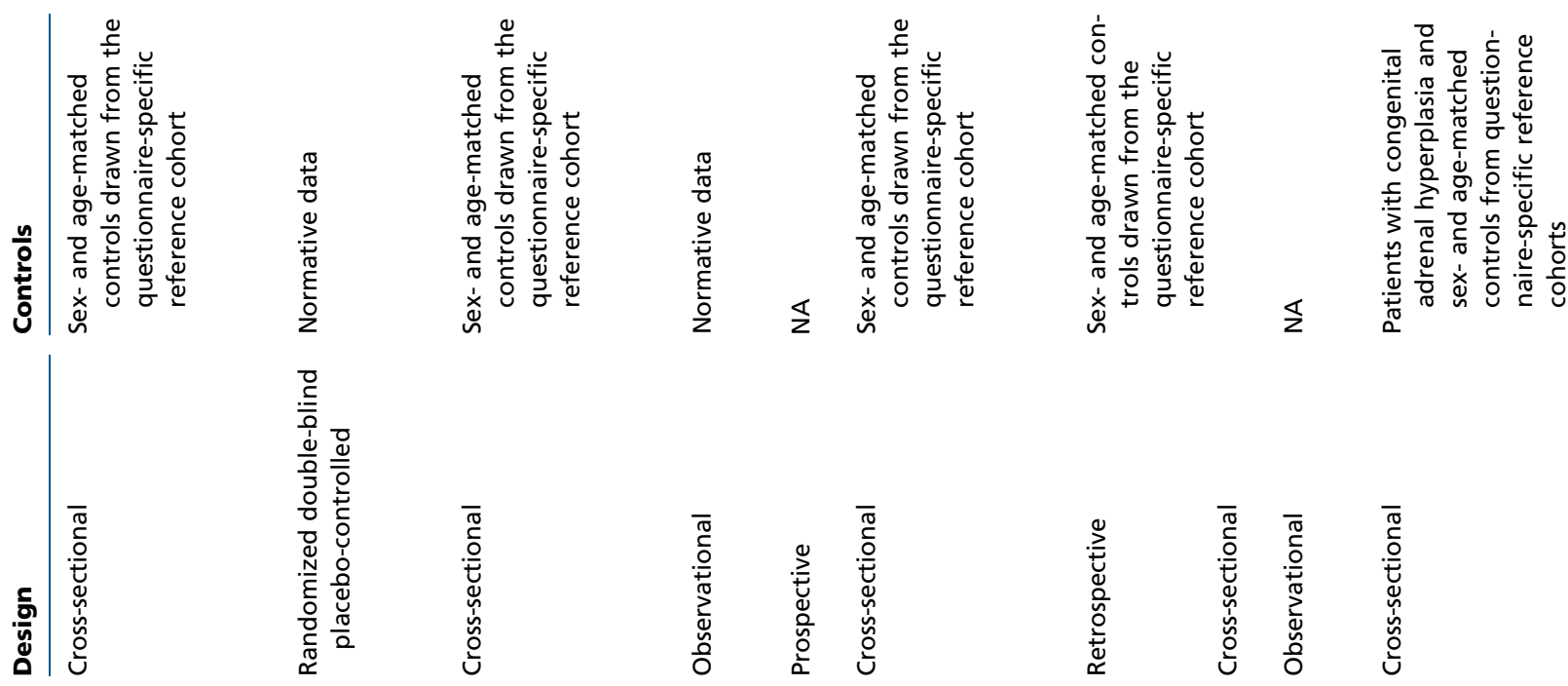

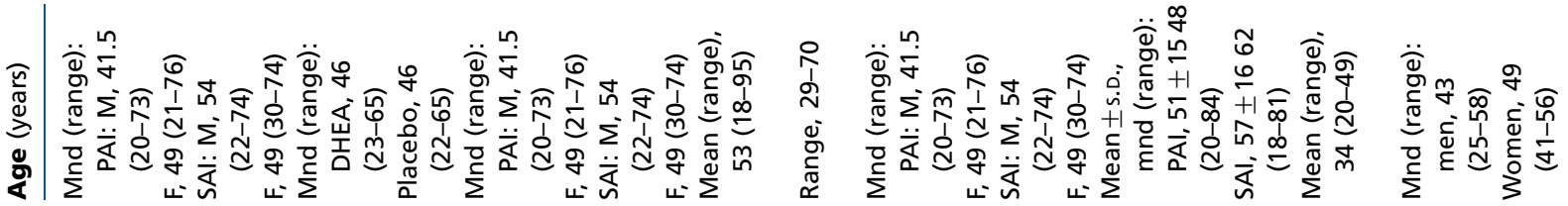

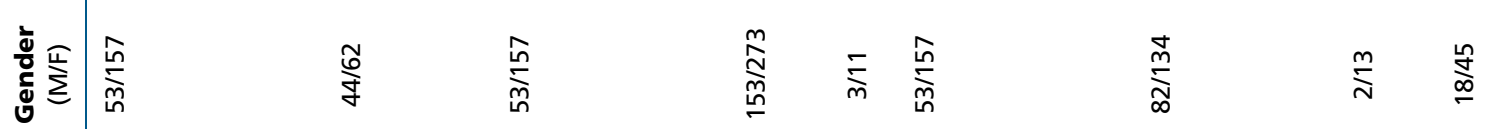

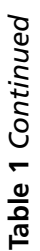
$=\frac{1}{i}$

$\stackrel{\circ}{\circ}$

$\stackrel{\circ}{i}$

$\stackrel{\Im}{\square} \stackrel{\circ}{\sim}$

$\stackrel{\circ}{\sim}$

$\stackrel{\wp}{\sim}$

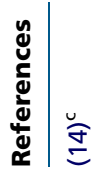

$\widehat{m} \quad \stackrel{\circlearrowright}{=}$

ฐ

㩊

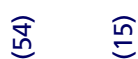




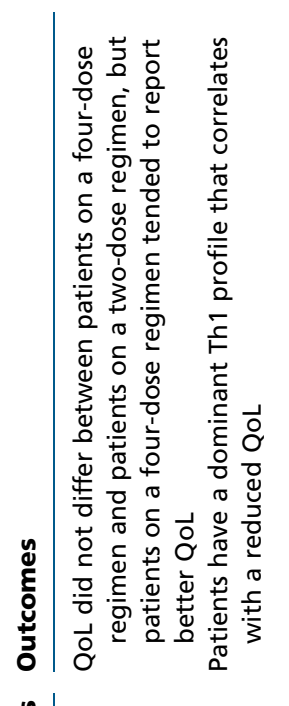

蒙|-

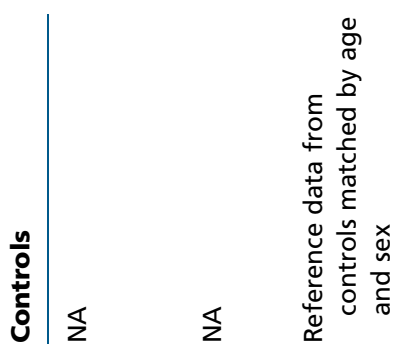

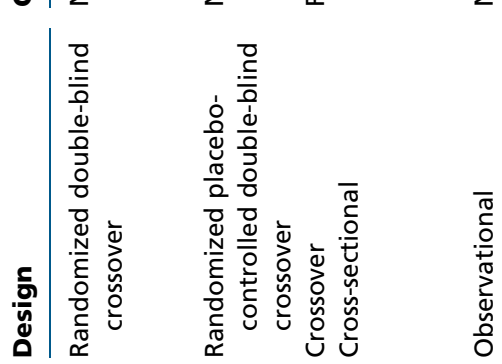

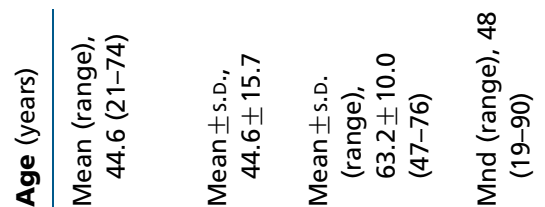

ঠ⿺辶寸

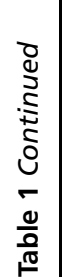

s $\stackrel{\llcorner}{\sim}$

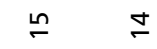

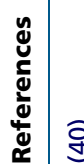

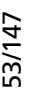

ণ
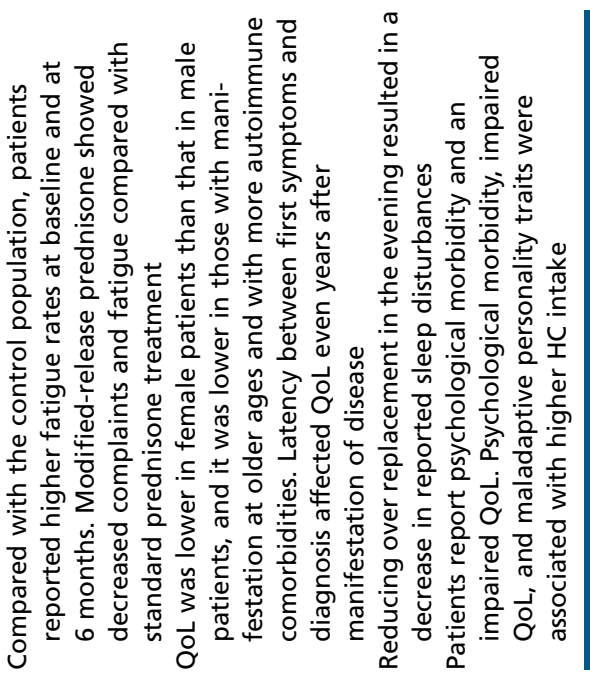

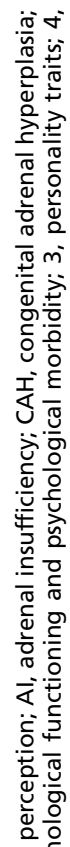

$-\stackrel{n}{N}$

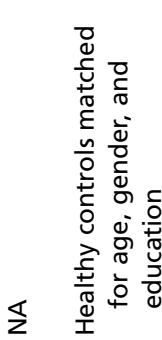

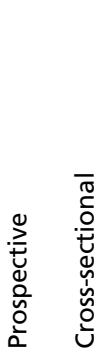

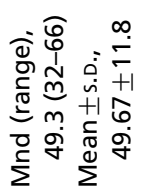

$\underset{\infty}{\stackrel{m}{\sim}} \stackrel{m}{\stackrel{m}{\sim}}$

ำ ㄴํ

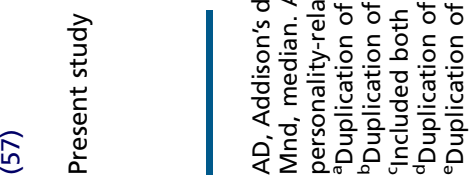


classification (32). The presence of symptoms is rated on a severity scale from 0 to 3 . We excluded the gender-specific items $(n=4)$ from the analyses to rule out bias by gender. The total symptom score ranges from 0 to 153. A higher score indicates more (severe) physical symptoms in the preceding week (33).

The Dimensional Assessment of Personality Pathology short form (DAPPs) consists of 136 items to assess personality traits, which are subdivided into 18 subscales: submissiveness, cognitive distortion, identity problems, affective lability, stimulus seeking, compulsivity, restricted expression, callousness, oppositionality, intimacy problems, rejection, anxiousness, conduct problems, suspiciousness, social avoidance, narcissism, insecure attachment, and self-harm. The score for each subscale differs with maxima of 30-40, with higher scores indicating more pronounced maladaptive personality traits (34).

\section{Statistical analysis}

Data were analyzed using IBM SPSS Statistics, version 20.0.0 (SPSS, Inc.). All data were presented as mean \pm s.D., unless mentioned otherwise. The primary analysis comprised the scores on the questionnaires, comparing between patients with stable treatment for PAI and healthy matched controls. To check the normality of data, the Kolmogorov-Smirnov test was used in addition to histograms and boxplots. Groups were compared using independent samples $t$-test. A Mann-Whitney $U$ test was used in case of non-parametric data. $\chi^{2}$ was used in case of categorical data. Because of multiple comparisons, the level of significance for this analysis was set at $P \leq 0.01$. The secondary analysis comprised the relationship between the scores on the various questionnaires and the mean daily dose of hydrocortisone, using a stepwise linear regression model. We included age and gender as additional independent variables. Because of the exploratory nature of this secondary analysis, adjustment of the level of significance for multiple testing was not performed, and the level of significance was set at $P \leq 0.05$.

\section{Results}

\section{Sociodemographic and clinical characteristics}

A total of 54 patients with PAI and 54 healthy controls, matched for gender, age, and education, were included. All patients were on stable hydrocortisone and fludrocortisone replacement therapy for a mean duration of $10.1 \pm$ 8.5 years (range, 2-38 years), as prescribed by their
Table 2 Clinical characteristics of patients with PAI. Data are noted in mean (s.D.) or number and percentage (\%). Patients with PAI and matched controls did not differ on any characteristic.

\begin{tabular}{|c|c|c|}
\hline & PAI $(n=54)$ & $\begin{array}{l}\text { Matched controls } \\
(n=54)\end{array}$ \\
\hline Gender (M/F) & $21 / 33$ & $21 / 33$ \\
\hline Age (years) & $49.67(11.8)$ & $49.26(12.5)$ \\
\hline Educational level & $\begin{array}{l}\text { Low: } 10(19 \%) \\
\text { Medium: } 21(39 \%) \\
\text { High: } 23(43 \%) \\
\text { Unknown: } 0\end{array}$ & $\begin{array}{l}\text { Low: } 9(17 \%) \\
\text { Medium: } 22(41 \%) \\
\text { High: } 22(41 \%) \\
\text { Unknown: } 1(2 \%)\end{array}$ \\
\hline BMI & $26.42(5.3)$ & NA \\
\hline PAl diagnosis & $\begin{array}{l}\text { Al: } 44(82 \%) \\
\text { Non-Al: } 5(9 \%) \\
\text { BA: } 2(4 \%) \\
\text { Unknown: } 3(5 \%)\end{array}$ & NA \\
\hline Hydrocortisone dose ${ }^{a}$ & $24.90(7.2)$ & NA \\
\hline Florinef & $45(83 \%)$ & NA \\
\hline DHEA & $14(26 \%)$ & NA \\
\hline Levothyroxine $^{b}$ & $25(46 \%)$ & NA \\
\hline Oral contraceptive & $2(11 \%)$ & NA \\
\hline Anti-hypertensives & $7(13 \%)$ & NA \\
\hline Menopause & $15(45 \%)$ & NA \\
\hline
\end{tabular}

PAI, primary adrenal insufficiency; NA, not applicable; Al, autoimmune; BA, bilateral adrenalectomy.

${ }^{\text {aT } T o t a l}$ dose per day.

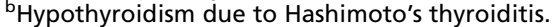

individual physicians (mean daily hydrocortisone intake of $25 \pm 7 \mathrm{mg}$ (range, $10-50 \mathrm{mg}$ ), divided in two to three dosages). Eighty-three percent of the patients also used fludrocortisone in addition to hydrocortisone. Additional medical therapy included DHEA (26\% of patients), levothyroxine (46\%), anti-hypertensive drugs (13\%), and oral contraceptives (9\%). Sixty-five percent of female patients were postmenopausal (Tables 2 and 3 ).

\section{Psychological functioning and QoL}

Patients with PAI had a higher total score on the Irritability Scale $(P=0.004)$ compared with matched controls. Patients also showed higher scores on the somatic arousal subscale of the MASQ-30 $(P=0.003)$. Clinically significant apathy and irritability (a score of $\geq 14$ on the Apathy Scale and on the Irritability Scale) was present in 35 and 33\% of patients, respectively, and significantly more irritability was observed in patients than in controls $(P=0.01)$. On the HADS, $11 \%$ of patients had a score of $\geq 8$ on the anxiety subscale and $6 \%$ on the depression subscale. This is indicative for the presence of clinically relevant anxiety or depression respectively. There were no significant differences between patients and controls on the depression subscale, anxiety subscale, or total HADS score (Table 4). 
Table 3 Clinical characteristics of PAl subjects. Data are noted in mean (S.D.) or number and percentage (\%).

\begin{tabular}{|c|c|c|}
\hline & $\begin{array}{l}\text { Males with } \\
\text { PAI }(n=21)\end{array}$ & $\begin{array}{l}\text { Females with } \\
\text { PAI }(n=33)\end{array}$ \\
\hline Age (years) & $48.48(13.1)$ & $50.52(11.0)$ \\
\hline \multirow[t]{3}{*}{ Educational level } & Low: 3 (14\%) & Low: 7 (21\%) \\
\hline & Medium: $9(43 \%)$ & Medium: $12(36 \%)$ \\
\hline & High: $9(43 \%)$ & High: $14(42 \%)$ \\
\hline BMI & $26.12(3.6)$ & $26.62(6.3)$ \\
\hline \multirow[t]{4}{*}{ PAl diagnose } & Al: $17(81 \%)$ & Al: $27(82 \%)$ \\
\hline & Non-Al: $2(10 \%)$ & Non-Al: $3(9 \%)$ \\
\hline & BA: $2(10 \%)$ & BA: 0 \\
\hline & Unknown: 0 & Unknown: 3 (9\%) \\
\hline Hydrocortisone dose $\mathrm{a}^{\mathrm{a}}$ & $26.90(6.8)$ & $23.62(7.3)$ \\
\hline Florinef & $16(76 \%)$ & $29(88 \%)$ \\
\hline DHEA & $2(10 \%)$ & $12(36 \%)$ \\
\hline Levothyroxine $^{\mathrm{b}}$ & $6(29 \%)$ & $19(58 \%)$ \\
\hline Oral contraceptive & NA & $2(11 \%)$ \\
\hline Anti-hypertensives & $3(14 \%)$ & $4(12 \%)$ \\
\hline Menopause & NA & $15(45 \%)$ \\
\hline
\end{tabular}

PAI, primary adrenal insufficiency; NA, not applicable; Al, autoimmune; BA, bilateral adrenalectomy.

${ }^{\text {a }}$ Total dose per day.

'Hypothyroidism due to Hashimoto's thyroiditis.

Patients scored worse on all subscales of the MFI-20 compared with matched controls, i.e. general fatigue $(P<0.001)$, physical fatigue $(P<0.001)$, reduced activity $(P=0.003)$, reduced motivation $(P=0.006)$, and mental fatigue $(P<0.001)$. Patients with PAI also scored worse on the physical functioning subscale $(P<0.001)$, social functioning subscale $(P=0.001)$, role limitation (physical) subscale $(P<0.001)$, vitality subscale $(P=0.009)$, and general health perception subscale $(P<0.001)$ of the SF-36. On the EQ-5D, patients scored worse than matched controls on activity $(P<0.001)$ and the VAS $(P<0.001)$. Furthermore, patients scored worse on energy $(P<0.001)$ and physical ability $(P<0.001)$ compared with matched controls as measured with the NHP. Lastly, patients reported more general/neurological symptoms $(P<0.001)$, autonomic symptoms $(P<0.001)$, genital symptoms $(P=0.002)$, and feeling hot/cold $(P<0.001)$ on the PSC compared with matched controls.

\section{Personality traits}

The scores of the patients on the DAPPs personality traits were not different from those of the matched controls.

\section{The association with daily hydrocortisone intake}

Higher hydrocortisone intake was associated with lower psychological well-being, more maladaptive personality traits, and more impaired QoL. More specifically, a higher dose of hydrocortisone was associated with more depressive symptoms (HADS Depression subscale, $\beta=0.282$, $P=0.038$ ), as well as decreased physical functioning $(\beta=-0.365, P=0.008)$, more physical role limitations $(\beta=-0.329, P=0.015)$, and more pain $(\beta=-0.272$, $P=0.047)$ (all SF-36 subscales). Moreover, the SF-36 subscale vitality was negatively associated with gender ( $\beta=-0.284, P=0.039)$, indicating that females reported less vitality. Furthermore, a higher hydrocortisone intake was associated with worse scores on mobility $(\beta=0.345$, $P=0.011)$ and the VAS $(\beta=-0.335, P=0.013)$ of the EQ$5 \mathrm{D}$. Lastly, a higher hydrocortisone intake was associated with several maladaptive personality traits, including more cognitive distortion $(\beta=0.288, P=0.037)$, identity problems $(\beta=0.474, P=0.000)$ (Fig. 1), compulsivity $(\beta=0.302, P=0.029)$, restricted expression $(\beta=0.277$, $P=0.042)$, callousness $(\beta=0.376, P=0.005)$, oppositionality $(\beta=0.291, P=0.035)$, rejection $(\beta=0.282, P=0.043)$,

Table 4 Psychological functioning, QoL, and personality in patients with PAI. Data are noted in mean (s.D.); only significant results are listed.

\begin{tabular}{|c|c|c|c|}
\hline & PAI $(n=54)$ & $\begin{array}{c}\text { Matched } \\
\text { controls } \\
(n=54)\end{array}$ & $P$ value \\
\hline \multicolumn{4}{|l|}{ Irritability scale } \\
\hline Total score & $11.32(7.0)$ & $7.78(5.3)$ & 0.004 \\
\hline Score $\geq 14, n(\%)$ & $18(33 \%)$ & $7(13 \%)$ & 0.010 \\
\hline \multicolumn{4}{|l|}{ MASQ-30 } \\
\hline Somatic arousal & $15.49(7.0)$ & $12.00(2.6)$ & 0.003 \\
\hline \multicolumn{4}{|l|}{ MFI-20 } \\
\hline General fatigue & $12.15(5.5)$ & $7.21(3.5)$ & $<0.001$ * \\
\hline Physical fatigue & $11.04(5.1)$ & $6.83(2.6)$ & $<0.001 *$ \\
\hline Reduced activity & $9.72(4.1)$ & 7.40 (3.3) & 0.003 \\
\hline Reduced motivation & $8.67(3.5)$ & $6.87(3.0)$ & 0.006 \\
\hline Mental fatigue & $11.08(4.4)$ & $7.38(2.9)$ & $<0.001 *$ \\
\hline \multicolumn{4}{|l|}{ SF-36 } \\
\hline Physical functioning & $80.29(19.6)$ & $94.15(7.7)$ & $<0.001 *$ \\
\hline Social functioning & $77.12(24.5)$ & $91.27(14.6)$ & 0.001 \\
\hline Role limitation (physical) & $65.28(43.8)$ & $93.75(17.8)$ & $<0.001 *$ \\
\hline Vitality & $48.21(9.8)$ & $52.92(8.5)$ & 0.009 \\
\hline $\begin{array}{l}\text { General health } \\
\text { perception }\end{array}$ & $54.06(26.1)$ & $77.31(15.5)$ & $<0.001 *$ \\
\hline \multicolumn{4}{|l|}{ EQ-5D } \\
\hline Activity & $1.35(0.5)$ & $1.06(0.2)$ & $<0.001 *$ \\
\hline VAS & 72.66 (15.9) & $84.12(10.2)$ & $<0.001 *$ \\
\hline \multicolumn{4}{|l|}{ NHP } \\
\hline Energy & $0.29(0.4)$ & $0.03(0.1)$ & $<0.001 *$ \\
\hline Physical ability & $0.09(0.1)$ & $0.01(0.0)$ & $<0.001 *$ \\
\hline \multicolumn{4}{|l|}{ PSC } \\
\hline General/neurological & $0.73(0.5)$ & $0.35(0.2)$ & $<0.001 *$ \\
\hline Autonomic symptoms & $0.53(0.4)$ & $0.16(0.2)$ & $<0.001 *$ \\
\hline Genital symptoms & $0.29(0.4)$ & $0.11(0.2)$ & 0.002 \\
\hline Feeling hot/cold & $0.79(0.7)$ & $0.27(0.3)$ & $<0.001 *$ \\
\hline
\end{tabular}

Level of significance was set at ${ }^{*} P \leq 0.01$, adjusting for multiple testing. 


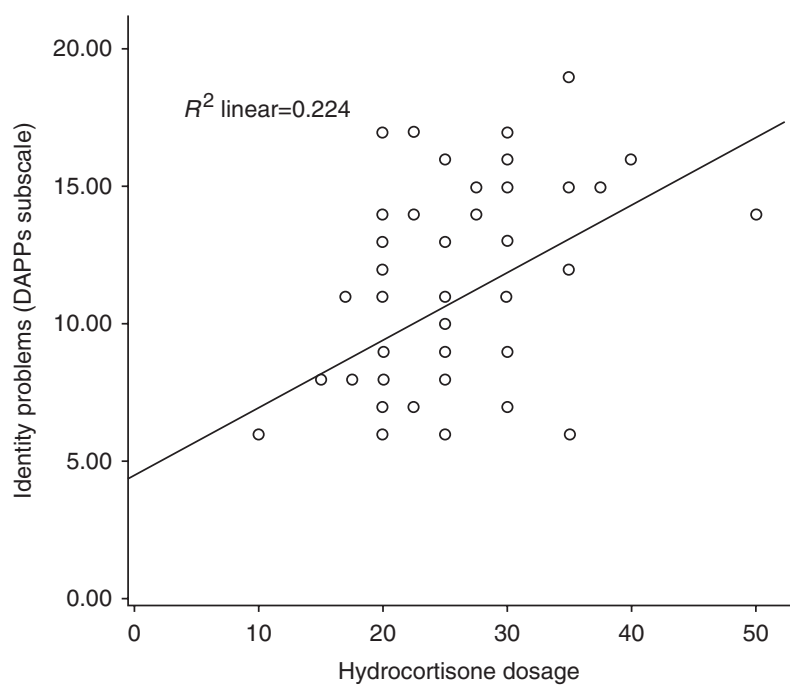

Figure 1

Association between hydrocortisone dosage and identity problems.

social avoidance $(\beta=0.316, P=0.021)$, and narcissism $(\beta=0.273, P=0.036)$. Moreover, narcissism $(\beta=-0.337$, $P=0.010)$ was negatively associated with age and selfharm was positively associated with age $(\beta=0.324$, $P=0.017)$. Female patients reported more conduct problems $(\beta=-0.358, P=0.008$; Table 5$)$.

\section{Discussion}

This study demonstrates that patients with stable treatment for PAI suffer from more psychological morbidity with irritability and somatic arousal, in addition to impairments of QoL compared with matched healthy controls. However, personality traits were not different between patients and controls, which indicates that personality traits in patients with PAI, in contrast to psychological functioning, are not sensitive to the effects of a chronic disease, such as PAI and its pharmacological treatment in contrast to psychological morbidity. To our knowledge, this is the first study on personality traits in patients with PAI. Interestingly, there was a strong and consistent association between the mean daily hydrocortisone dose and the prevalence of maladaptive personality traits, such as cognitive distortion, identity problems, and compulsivity, and also with restricted expression, callousness, oppositionality, rejection, social avoidance, and narcissism. Furthermore, there was a strong positive relation between the mean daily hydrocortisone intake and reported psychological morbidity (i.e. depression) and
QoL impairments (i.e. several measures of physical functioning and pain).

Previous studies by our group have shown similar results with regard to psychological functioning and QoL in patients in long-term remission of Cushing's disease, though patients in remission of Cushing's disease also showed more maladaptive personality traits than their matched controls $(3,4,5,35)$. These observations suggest that psychological functioning and QoL indeed follow the inverted u-shape dose-response curve of cortisol exposure related to MR and GR activation, whereas this is not the case for personality traits and lower cortisol levels. Intriguingly, higher daily hydrocortisone intake seemed to be strongly associated with maladaptive personality traits, indicating that hydrocortisone intake does have a considerable effect on personality traits in patients with AI.

Our findings regarding QoL are in line with the results of previous studies on decreased QoL in patients with AI $(9,14,36,37)$ and the self-reported impact of the disease or treatment on subjective health status (38). In addition,

Table 5 Influence of daily hydrocortisone dosage, age, and gender on dimensions in the questionnaires. There were no significant associations between daily hydrocortisone dosage, age and gender, and scores on the Apathy scale, Irritability scale, MAQ-30, MVI-20, NHP, and PSC.

\begin{tabular}{|c|c|c|c|}
\hline & $\begin{array}{l}\text { Hydro- } \\
\text { cortisone } \\
\text { dosage }\end{array}$ & Age & Gender \\
\hline \multicolumn{4}{|l|}{ HADS } \\
\hline Depression & $\beta=0.282^{*}$ & & \\
\hline \multicolumn{4}{|l|}{ SF-36 } \\
\hline Physical functioning & $\beta=-0.365^{\dagger}$ & & \\
\hline $\begin{array}{l}\text { Role limitation } \\
\text { (physical) }\end{array}$ & $\beta=-0.329 *$ & & \\
\hline Vitality & & & $\beta=-0.284^{*}$ \\
\hline Pain & $\beta=-0.272^{*}$ & & \\
\hline \multicolumn{4}{|l|}{ EQ-5D } \\
\hline Mobility & $\beta=0.345^{*}$ & & \\
\hline VAS & $\beta=-0.335^{*}$ & & \\
\hline \multicolumn{4}{|l|}{ DAPP } \\
\hline Cognitive distortion & $\beta=0.288^{*}$ & & \\
\hline Identity problems & $\beta=0.474^{\dagger}$ & & \\
\hline Compulsivity & $\beta=0.302 *$ & & \\
\hline $\begin{array}{l}\text { Restricted } \\
\text { expression }\end{array}$ & $\beta=0.277^{*}$ & & \\
\hline Callousness & $\beta=0.376^{*}$ & & \\
\hline Oppositionality & $\beta=0.291$ * & & \\
\hline Rejection & $\beta=0.282^{*}$ & & \\
\hline Conduct problems & & & $\beta=-0.358^{\dagger}$ \\
\hline Social avoidance & $\beta=0.316^{*}$ & & \\
\hline Narcissism & $\beta=0.273^{*}$ & $\beta=-0.337 *$ & \\
\hline Self-harm & & $\beta=0.324^{*}$ & \\
\hline
\end{tabular}

Only associations that reached statistical significance $(* P<0.05$ and $\left.{ }^{\dagger} P<0.01\right)$ are depicted. 
several QoL studies demonstrated that inadequate hydrocortisone replacement dosages and, especially, high hydrocortisone dosages negatively affected QoL $(11,37$, $39,40)$. Accordingly, we found negative effects of high hydrocortisone intake on QoL in patients with PAI. Intriguingly, we also found a negative effect of high hydrocortisone intake on psychological morbidity and the prevalence of maladaptive personality traits.

In healthy individuals, cortisol is secreted in a pulsatile fashion with a superimposed circadian rhythm. It is actually impossible to mimic this normal pattern of hormonal secretion by hydrocortisone replacement. These imperfections in pharmacotherapy are, at least in part, associated with persistent vague complaints and a decreased QoL (9). The importance of mimicking the circadian rhythm of cortisol secretion in patients with AI is supported by a study of Johannsson et al. (41), which demonstrated that in patients treated with once-daily dual-release hydrocortisone tablets, a more circadianbased cortisol profile and more favorable scores on questionnaires assessing psychological well-being and fatigue were observed, compared with patients treated with conventional hydrocortisone treatment. Furthermore, both Løvås \& Husebye (42) and Oksnes et al. (43) reported that continuous hydrocortisone infusion in patients with PAI resulted in cortisol and ACTH levels toward normal circadian levels and positively affected QoL. These two studies suggest that the physiological profile might be related to QoL outcomes.

A previous study by Thomsen et al. (16) reported an increased risk for developing affective disorders (e.g. depression, bipolar disorder) in hospitalized patients with AI. In our cohort of patients with stable PAI, we did not find differences in depressive symptoms between patients and healthy controls. However, considering the fact that we did find other psychological morbidity (i.e. irritability and somatic arousal), we postulate that even after correction of hypocortisolism, patients with PAI remain vulnerable for developing psychological and, in particular, mood symptoms.

Recently, gender, manifestation at older age, more autoimmune comorbidities, and latency between first symptoms and diagnosis have been found to negatively affect QoL in patients with AI (44). Our data indicate that the amount of daily hydrocortisone intake should also be included as a potential influencing factor of QoL. Nevertheless, because of the exploratory nature of our study, future research is needed to provide more insights into predictors of reduced QoL in patients with AI and to further distinguish whether the QoL impairments are caused by the disease itself or its treatment. In addition to the focus on research about somatic predictor variables, researchers should pay attention to potential psychological contributing factors, such as negative illness perceptions and ineffective coping strategies, because recent data have indicated that negative illness perceptions were related to a decreased QoL in patients in long-term remission of Cushing's diseases (45).

A possible limitation of this study is the crosssectional design, which does not preclude that maladaptive personality traits and QoL impairments were already present before the onset of the disease. Furthermore, we cannot simply conclude that high hydrocortisone intake causes a decreased QoL, because it might be that high hydrocortisone dosages were prescribed because patients suffered from psychological symptoms or a decreased QoL. Therefore, future studies should use a longitudinal design to enable the evaluation of the course of psychological functioning, QoL, and personality, and of the influence of adaptations in hydrocortisone intake on these three domains over time. A longitudinal design might also elucidate the interesting discrepancy between our finding that personality traits of patients with PAI do not differ from healthy controls, whereas higher daily hydrocortisone intake is significantly associated with maladaptive personality traits in patients with PAI.

In summary, patients with stable treatment for PAI report psychological morbidity and impaired QoL. There is a positive association between the daily hydrocortisone intake and the presence of psychological morbidity, maladaptive personality traits, and QoL impairments. These results point toward the possibility to intertwine psychosocial parameters in care for patients with endocrine replacement in general, and for patients with AI specifically. This approach would open the area of self-management research in this patient category, which has already been shown to have positive effects on QoL in patients with other chronic somatic diseases $(46,47,48)$.

\section{Declaration of interest}

The authors declare that there is no conflict of interest that could be perceived as prejudicing the impartiality of the research reported.

\section{Funding}

This research did not receive any specific grant from any funding agency in the public, commercial or not-for-profit sector. 


\section{References}

1 De Kloet ER, Vreugdenhil E, Oitzl MS \& Joels M. Brain corticosteroid receptor balance in health and disease. Endocrine Reviews 199819 269-301. (doi:10.1210/edrv.19.3.0331)

2 Feelders RA, Pulgar SJ, Kempel A \& Pereira AM. The burden of Cushing's disease: clinical and health-related quality of life aspects. European Journal of Endocrinology 2012167 311-326. (doi:10.1530/EJE-11-1095)

3 Tiemensma J, Biermasz NR, Middelkoop HA, van der Mast RC, Romijn JA \& Pereira AM. Increased prevalence of psychopathology and maladaptive personality traits after long-term cure of Cushing's disease. Journal of Clinical Endocrinology and Metabolism 201095 E129-E141. (doi:10.1210/jc.2010-0512)

4 Van Aken MO, Pereira AM, Biermasz NR, van Thiel SW, Hoftijzer HC, Smit JW, Roelfsema F, Lamberts SW \& Romijn JA. Quality of life in patients after long-term biochemical cure of Cushing's disease. Journal of Clinical Endocrinology and Metabolism 200590 3279-3286. (doi:10.1210/jc.2004-1375)

5 Van der Klaauw AA, Kars M, Biermasz NR, Roelfsema F, Dekkers OM, Corssmit EP, van Aken MO, Havekes B, Pereira AM, Pijl H et al. Diseasespecific impairments in quality of life during long-term follow-up of patients with different pituitary adenomas. Clinical Endocrinology 2008 69 775-784. (doi:10.1111/j.1365-2265.2008.03288.x)

6 Wagenmakers MA, Netea-Maier RT, Prins JB, Dekkers T, den Heijer M \& Hermus AR. Impaired quality of life in patients in long-term remission of Cushing's syndrome of both adrenal and pituitary origin: a remaining effect of long-standing hypercortisolism? European Journal of Endocrinology 2012167 687-695. (doi:10.1530/EJE-12-0308)

7 Ragnarsson O, Berglund P, Eder DN \& Johannsson G. Long-term cognitive impairments and attentional deficits in patients with Cushing's disease and cortisol-producing adrenal adenoma in remission. Journal of Clinical Endocrinology and Metabolism 201297 E1640-E1648. (doi:10.1210/jc.2012-1945)

8 Heijmans $\mathrm{M} \&$ de Ridder D. Assessing illness representations of chronic illness: explorations of their disease-specific nature. Journal of Behavioral Medicine 199821 485-503. (doi:10.1023/A:1018788427100)

9 Alonso N, Granada ML, Lucas A, Salinas I, Reverter J, Oriol A \& Sanmarti A. Evaluation of two replacement regimens in primary adrenal insufficiency patients. effect on clinical symptoms, healthrelated quality of life and biochemical parameters. Journal of Endocrinological Investigation 200427 449-454. (doi:10.1007/BF03345290)

10 Bleicken B, Hahner S, Loeffler M, Ventz M, Allolio B \& Quinkler M. Impaired subjective health status in chronic adrenal insufficiency: impact of different glucocorticoid replacement regimens. European Journal of Endocrinology 2008159 811-817. (doi:10.1530/EJE-08-0578)

11 Bleicken B, Hahner S, Loeffler M, Ventz M, Decker O, Allolio B \& Quinkler M. Influence of hydrocortisone dosage scheme on healthrelated quality of life in patients with adrenal insufficiency. Clinical Endocrinology 201072 297-304. (doi:10.1111/j.1365-2265.2009.03596.x)

12 Erichsen MM, Løvås K, Skinningsrud $\mathrm{B}$, Wolff $\mathrm{AB}$, Undlien $\mathrm{DE}$, Svartberg J, Fougner KJ, Berg TJ, Bollerslev J, Mella B et al. Clinical, immunological, and genetic features of autoimmune primary adrenal insufficiency: observations from a Norwegian registry. Journal of Clinical Endocrinology and Metabolism 200994 4882-4890. (doi:10.1210/jc. 2009-1368)

13 Gurnell EM, Hunt PJ, Curran SE, Conway CL, Pullenayegum EM, Huppert FA, Compston JE, Herbert J \& Chatterjee VK. Long-term DHEA replacement in primary adrenal insufficiency: a randomized, controlled trial. Journal of Clinical Endocrinology and Metabolism 200893 400-409. (doi:10.1210/jc.2007-1134)

14 Hahner S, Loeffler M, Fassnacht M, Weismann D, Koschker A-C, Quinkler M, Decker O, Arlt W \& Allolio B. Impaired subjective health status in 256 patients with adrenal insufficiency on standard therapy based on cross-sectional analysis. Journal of Clinical Endocrinology and Metabolism 200792 3912-3922. (doi:10.1210/jc.2007-0685)
15 Reisch N, Hahner S, Bleicken B, Flade L, Pe drosaGil F, Loeffler M, Ventz M, Hinz A, Beuschlein F, Allolio B et al. Quality of life is less impaired in adults with congenital adrenal hyperplasia because of 21-hydroxylase deficiency than in patients with primary adrenal insufficiency. Clinical Endocrinology 201174 166-173. (doi:10.1111/j. 1365-2265.2010.03920.x)

16 Thomsen AF, Kvist TK, Andersen PK \& Kessing LV. The risk of affective disorders in patients with adrenocortical insufficiency. Psychoneuroendocrinology 200631 614-622. (doi:10.1016/j.psyneuen.2006.01.003)

17 Arlt W, Callies F \& Allolio B. DHEA replacement in women with adrenal insufficiency - pharmacokinetics, bioconversion and clinical effects on well-being, sexuality and cognition. Endocrine Research 2000 26 505-511. (doi:10.3109/07435800009048561)

18 Arlt W, Callies F, van Vlijmen JC, Koehler I, Reincke M, Bidlingmaier M, Huebler D, Oettel M, Ernst M, Schulte HM et al. Dehydroepiandrosterone replacement in women with adrenal insufficiency. New England Journal of Medicine 1999341 1013-1020. (doi:10.1056/ NEJM199909303411401)

19 Hunt PJ, Gurnell EM, Huppert FA, Richards C, Prevost AT, Wass JA, Herbert J \& Chatterjee VK. Improvement in mood and fatigue after dehydroepiandrosterone replacement in Addison's disease in a randomized, double blind trial. Journal of Clinical Endocrinology and Metabolism 200085 4650-4656. (doi:10.1210/jcem.85.5.6588)

20 Harbeck B, Kropp P \& Mönig H. Effects of short-term nocturnal cortisol replacement on cognitive function and quality of life in patients with primary or secondary adrenal insufficiency: a pilot study. Applied Psychophysiology and Biofeedback 200934 113-119. (doi:10.1007/ s10484-009-9082-5)

21 Starkstein SE, Petracca G, Chemerinski E \& Kremer J. Syndromic validity of apathy in Alzheimer's disease. American Journal of Psychiatry 2001158 872-877. (doi:10.1176/appi.ajp.158.6.872)

22 Chatterjee A, Anderson KE, Moskowitz CB, Hauser WA \& Marder KS. A comparison of self-report and caregiver assessment of depression, apathy, and irritability in Huntington's disease. Journal of Neuropsychiatry and Clinical Neurosciences 200517 378-383. (doi:10.1176/appi. neuropsych.17.3.378)

23 Clark LA \& Watson D. Tripartite model of anxiety and depression: psychometric evidence and taxonomic implications. Journal of Abnormal Psychology 1991100 316-336. (doi:10.1037/0021-843X.100.3.316)

24 Spinhoven P, Ormel J, Sloekers PP, Kempen GI, Speckens AE \& Van Hemert AM. A validation study of the Hospital Anxiety and Depression Scale (HADS) in different groups of Dutch subjects. Psychological Medicine 199727 363-370. (doi:10.1017/ S0033291796004382)

25 Zigmond AS \& Snaith RP. The Hospital Anxiety and Depression Scale Acta Psychiatrica Scandinavica 198367 361-370. (doi:10.1111/j.16000447.1983.tb09716.x)

26 Smets EM, Garssen B, Bonke B \& De Haes JC. The Multidimensional Fatigue Inventory (MFI) psychometric qualities of an instrument to assess fatigue. Journal of Psychosomatic Research 199539 315-325. (doi:10.1016/0022-3999(94)00125-O)

27 Ware JE \& Sherbourne CD. The MOS 36-item short-form health survey (SF-36). I. Conceptual framework and item selection. Medical Care 1992 30 473-483. (doi:10.1097/00005650-199206000-00002)

28 Brazier JE, Harper R, Jones NM, O'Cathain A, Thomas KJ, Usherwood T \& Westlake L. Validating the SF-36 health survey questionnaire: new outcome measure for primary care. BMJ 1992305 160-164. (doi:10.1136/bmj.305.6846.160)

29 The EuroQol Group. EuroQol - a new facility for the measurement of health-related quality of life. The EuroQol Group. Health Policy (New York) 199016 199-208. (doi:10.1016/0168-8510(90)90421-9)

30 Hunt SM, McKenna SP, McEwen J, Backett EM, Williams J \& Papp E. A quantitative approach to perceived health status: a validation study. Journal of Epidemiology and Community Health 198034 281-286. (doi:10.1136/jech.34.4.281) 
31 Hunt SM \& McEwen J. The development of a subjective health indicator. Sociology of Health \& Illness 19802 231-246. (doi:10.1111/ 1467-9566.ep11340686)

32 American Psychiatric Association. In Diagnostic and Statistical Manual of Mental Disorders, Third Edition. Washington D.C.: APA, 1980.

33 de Waal MW, Arnold IA, Spinhoven P, Eekhof JA \& van Hemert AM. The reporting of specific physical symptoms for mental distress in general practice. Journal of Psychosomatic Research 200559 89-95. (doi:10.1016/j.jpsychores.2005.02.011)

34 Van Kampen D, de Beurs E \& Andrea H. A short form of the Dimensional Assessment of Personality Pathology-Basic Questionnaire (DAPP-BQ): the DAPP-SF. Psychiatry Research 2008160 115-128. (doi:10.1016/j.psychres.2007.05.002)

35 Pereira AM, Tiemensma J \& Romijn JA. Neuropsychiatric disorders in Cushing's syndrome. Neuroendocrinology 201092 65-70. (doi:10.1159/ 000314317)

36 Løvås K, Loge JH \& Husebye ES. Subjective health status in Norwegian patients with Addison's disease. Clinical Endocrinology 200256 581-588. (doi:10.1046/j.1365-2265.2002.01466.x)

37 Benson S, Neumann P, Unger N, Schedlowski M, Mann K, Elsenbruch S $\&$ Petersenn N. Effects of standard glucocorticoid replacement therapies on subjective well-being: a randomized, double-blind, crossover study in patients with secondary adrenal insufficiency. European Journal of Endocrinology 2012167 679-685. (doi:10.1530/ EJE-12-0351)

38 Forss M, Batcheller G, Skrtic S \& Johannsson G. Current practice of glucocorticoid replacement therapy and patient-perceived health outcomes in adrenal insufficiency - a worldwide patient survey. BMC Endocrine Disorders 201212 8. (doi:10.1186/1472-6823-12-8)

39 Riedel M, Wiese A, Schürmeyer TH \& Brabant G. Quality of life in patients with Addison's disease: effects of different cortisol replacement modes. Experimental and Clinical Endocrinology 1993101 106-111. (doi:10.1055/s-0029-1211215)

40 Ekman B, Bachrach-Lindström M, Lindström T, Wahlberg J, Blomgren J \& Arnqvist HJ. A randomized, double-blind, crossover study comparing two- and four-dose hydrocortisone regimen with regard to quality of life, cortisol and ACTH profiles in patients with primary adrenal insufficiency. Clinical Endocrinology 201277 18-25. (doi:10.1111/ j.1365-2265.2012.04352.x)

41 Johannsson G, Nilsson AG, Bergthorsdottir R, Burman P, Dahlqvist P, Ekman B, Engström BE, Olsson T, Ragnarsson O, Ryberg $\mathrm{M}$ et al. Improved cortisol exposure-time profile and outcome in patients with adrenal insufficiency: a prospective randomized trial of a novel hydrocortisone dual-release formulation. Journal of Clinical Endocrinology and Metabolism 201297 473-481. (doi:10.1210/jc.2011-1926)

42 Løvås K \& Husebye ES. Continuous subcutaneous hydrocortisone infusion in Addison's disease. European Journal of Endocrinology 2007 157 109-112. (doi:10.1530/EJE-07-0052)

43 Oksnes M, Björnsdottir S, Isaksson M, Methlie P, Carlsen S, Nilsen RM, Broman JE, Triebner K, Kampe O, Hulting AL et al. Continuous subcutaneous hydrocortisone infusion versus oral hydrocortisone replacement for treatment of Addison's disease: a randomized clinical trial. Journal of Clinical Endocrinology and Metabolism 201499 1665-1674. (doi:10.1210/jc.2013-4253)
44 Meyer G, Hackemann A, Penna-Martinez M \& Badenhoop K. What affects the quality of life in autoimmune Addison's disease? Hormone and Metabolic Research 201345 92-95. (doi:10.1055/s-0032-1331766)

45 Tiemensma J, Kaptein AA, Pereira AM, Smit JW, Romijn JA \& Biermasz NR. Affected illness perceptions and the association with impaired quality of life in patients with long-term remission of acromegaly. Journal of Clinical Endocrinology and Metabolism 201196 3550-3558. (doi:10.1210/jc.2011-1645)

46 Newman S, Steed L \& Mulligan K. Self-management interventions for chronic illness. Lancet 2004364 1523-1537. (doi:10.1016/S01406736(04)17277-2)

47 Taylor SJ, Sohanpal R, Bremner SA, Devine A, McDaid D, Fernández J-L, Griffiths CJ \& Eldridge S. Self-management support for moderateto-severe chronic obstructive pulmonary disease: a pilot randomised controlled trial. British Journal of General Practice 201262 e687-e695. (doi:10.3399/bjgp12X656829)

48 Loh SY, Packer T, Chinna K \& Quek KF. Effectiveness of a patient self-management programme for breast cancer as a chronic illness: a non-randomised controlled clinical trial. Journal of Cancer Survivorship 20137 331-342. (doi:10.1007/s11764-013-0274-x)

49 Groves RW, Toms GC, Houghton BJ \& Monson JP. Corticosteroid replacement therapy: twice or thrice daily? Journal of the Royal Society of Medicine 198881 514-516. (doi:10.1177/014107688808100906)

50 Heijmans M \& De Ridder D. Structure and determinants of illness representations in chronic disease: a comparison of Addison's disease and chronic fatigue syndrome. Journal of Health Psychology 19983 523-537. (doi:10.1177/135910539800300406)

51 Heijmans M. The role of patients' illness representations in coping and functioning with Addison's disease. British Journal of Health Psychology 19994 137-149. (doi:10.1348/ 135910799168533)

52 Libè R, Barbetta L, Dall'Asta C, Salvaggio F, Gala C, Beck-Peccoz P \& Ambrosi B. Effects of dehydroepiandrosterone (DHEA) supplementation on hormonal, metabolic and behavioral status in patients with hypoadrenalism. Journal of Endocrinological Investigation 200427 736-741. (doi:10.1007/BF03347515)

53 Bleicken B, Hahner S, Ventz M \& Quinkler M. Delayed diagnosis of adrenal insufficiency is common: a cross-sectional study in 216 patients. American Journal of the Medical Sciences 2010339 525-531. (doi:10.1097/MAJ.0b013e3181db6b7a)

54 Warmuz-Stangierska I, Baszko-Błaszyk D \& Sowiński J. Emotions and features of temperament in patients with Addison's disease. Endokrynologia Polska 201061 90-92.

55 Ekman B, Alstrand N, Bachrach-Lindström M, Jenmalm MC \& Wahlberg J. Altered chemokine Th1/Th2 balance in Addison's disease: relationship with hydrocortisone dosing and quality of life. Hormone and Metabolic Research 201346 48-53. (doi:10.1055/s-00331351291)

56 Langenheim J, Ventz M, Hinz A \& Quinkler M. Modified-release prednisone decreases complaints and fatigue compared to standard prednisolone in patients with adrenal insufficiency. Hormone and Metabolic Research 201345 96-101. (doi:10.1055/s-0032-1316293)

57 Smans L, Lentjes E, Hermus A \& Zelissen P. Salivary cortisol day curves in assessing glucocorticoid replacement therapy in Addison's disease. Hormones 201312 93-100.

Received 10 January 2014

Revised version received 10 April 2014

Accepted 2 May 2014 